\title{
Yüzücü ve Sedanter Çocukların Vücut Kompozisyonu ve Bazı Fizyolojik Parametrelerinin Karşılaştırılması ${ }^{1}$
}

\section{Güner ÇiçEK ${ }^{1}$}

\author{
Abdullah GÜLLÜ ${ }^{1}$
}

\author{
Esin GÜLLÜ ${ }^{1}$
}

\author{
${ }^{1}$ Hitit Üniversitesi Spor Bilimleri Fakültesi, Beden Eğitimi ve Spor Eğitimi Bölümü, ÇORUM
}

Künye: Çiçek, G., Güllü, A. ve Güllü, E. (2018). Yüzücü ve Sedanter Çocukların Vücut Kompozisyonu ve Bazı Fizyolojik Parametrelerinin Karşılaştırılması. Gaziantep Üniversitesi Spor Bilimleri Dergisi, 3(2): 85-97.

\section{Öz}

$\mathrm{Bu}$ çalışmanın amacı yüzücü ve sedanter çocuklarda bazı fiziksel ve fizyolojik parametreleri karşılaştırmaktır. 16 yüzücü çocuk (ortalama yaşları: 10,75 $\pm 1,34$ yıl, boy: $146,56 \pm 9,16 \mathrm{~cm}$, vücut ağılığı: $42,76 \pm 14,05 \mathrm{~kg}$ ve spor yaşı $26.31 \pm 10.22$ ay ) ve 17

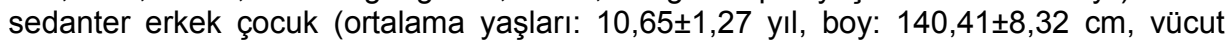
ağırlığı: $38,15 \pm 10,94 \mathrm{~kg}$ ) olan toplam 33 sağlıklı ve gönüllü çocuk bu çalışmaya katıldı. Bu çalışmada vücut ağırlığı, beden kütle indeksi (BKi), bazal metabolik hızı (BMH), vücut yağ kütlesi (VYK) ve vücut yağ yüzdesi (VYY) bioelektrik impedans analizi ile belirlendi. $\mathrm{MaxVO}_{2}$ ve kan basıncı için Bruce protokolü öncesi ve sonrası, el kavrama, otur- eriş ve dikey sıçrama testleri uygulandı. Gruplar arası karşılaştırmada istatiksel olarak önemlilik seviyesi $p<0.05$ kullanıldı. Yüzücü çocuk ve sedanter çocukların test değerleri karşılaştırıldığında Bruce protokolünden sonra $\mathrm{MaxVO}_{2}$ ve dikey sıçrama, sistolik ve diyastolik kan basınçları değerlerinde anlamlı farklılık bulundu $(p<0.05)$. Sonuç olarak, yüzücü çocukların kan basıncı, aerobik ve anaerobik kapasiteleri sedanter çocuklardan daha iyi olduğu bulundu. Bunun sebebi olarak yüzme sporunun düzenli olarak yapılmasının 10-13 yaş grubu erkek çocuklarda aerobik ve anaerobik kapasiteler ile sistolik ve diastolik kan basıncı parametreleri üzerinde olumlu bir etki sağladığı söylenebilir.

Anahtar Sözcükler: Yüzme, Anaerobik Güç, MaxVO, Esneklik, Vücut Kompozisyonu

\section{Orijinal Makale}

Yayın Bilgileri

Gönderi Tarihi: 05.05.2018

Kabul Tarihi: 06.06.2018

Yayın Tarihi: 20.06.2018

\section{Sorumlu Yazar}

e-mail: gullu.esn@gmail.com

DOI: $10.31680 / g a u n j s s .421261$

\section{Comparison of Body Composition and Some Physiological Parameters of Swimmer and Sedanter Children}

\begin{abstract}
It was aimed to compare some physical and physiological variables of swimmer and sedanter boys, in this study. 16 swimmer male children (mean age: 10,75 $\pm 1,34$ years, height: $146,56 \pm 9,16 \mathrm{~cm}$, weight: $42,76 \pm 14,05 \mathrm{~kg}$ and sport age $26.31 \pm 10.22$ months) were included in the sportsman group, and 17 healthy sedentary male children (mean age: $10,65 \pm 1,27$ years, height: $140,41 \pm 8,32 \mathrm{~cm}$ and weight: $38,15 \pm 10,94 \mathrm{~kg}$ ), to be totally 33 healthy and voluntary children participated in this study. The body weight, body mass index (BMI), basal metabolic rate (BMR), body fat mass (BFM) and body fat percentage (BF\%) of the study group were determined by bioelectrical impedance analysis. Bruce protocol for $\mathrm{VO}_{2 \mathrm{Max}}$ measurement, blood pressure before and after, hand grip, seat and reach and Sargent vertical jump tests were applied. $p<0.05$ level of significance was used in the intergroup comparison of the obtained data. When athlete's group and control group test values were compared, there was a significant difference in $\mathrm{VO}_{2} \mathrm{Max}$ and JT, systolic and diastolic blood pressure values after the Bruce Protocol $(p<0,05)$. According to the findings, it was observed that BP, aerobic and anaerobic capacities of swimmer children is better than the control group of children. For this reason, it can be said that performed regular swimming sports have a positive effect on aerobic and anaerobic capacities with on systolic and diastolic blood pressures in around 10-13year old boys.
\end{abstract}

Keywords: Swimming, Anaerobic Power, $\mathrm{VO}_{2} \mathrm{Max}$, Flexibility, Body Composition

\section{Original Article}

\section{Article Info}

Received: 05.05.2018

Accepted: 06.06.2018

Published: 20.06.2018

\section{Corresponding Author}

e-mail: gullu.esn@gmail.com

\footnotetext{
${ }^{1}$ Bu çalışma 9. Uluslararası Spor Sosyal Bilimler Topluluğu Konferansı'nda sözel bildiri olarak sunulmuştur.
} 


\section{Giriş}

Spor çocukların fiziksel, motorik, kognitif ve sosyal gelişiminde büyük rol oynar. Bu özellikler çocukluk ve gençlik döneminde kazanılır ve yaşam boyu korunarak bedenin en üst kapasitede işlev görebilmesi sağlanmış olur (Baltacı, 2008). Hayat boyu spor alışkanlığının kazandırılması ancak çocukluk çağında yapılacak egzersizler ile mümkündür. Bu yüzden çocuk ve gençleri birçok farklı spor dallarına yönlendirmek hızlı büyümenin en yüksek hızda olduğu süreçte fiziksel gelişimin desteklenmesi adına büyük önem taşımaktadır. Hızlı büyüme süreci kızlarda 9.5-15 yaş, erkeklerde 11-17 yaş olarak belirtilmektedir (Baltacı 2008). Bu dönemde büyüme hormonunun fazla salgılanmasına bağlı olarak boy uzaması ve ağırlık artışı çok hızlı olmakta (Haywood, 1986) ve fiziksel gelişimde biçimlenmektedir. Bireyin fiziki yapısı ile sinir ve kas sisteminin fonksiyonel değişim ve dengelenme süresi olarak tanımlanan fiziksel gelişim spor ile desteklenmelidir (Hickson ve Rosenkdetter, 1981). Genellikle sağlıklı yaşam için Dünya Sağlık Örgütünün önerdiği aktivitelerden biri olan yüzme sporu sadece sağlıklı yaşam için değil aynı zamanda profesyonel anlamda da uygulanan bir spor dalıdır (WHO, 2010). Yüzme, gelişim dönemindeki çocuklarımızın yapması gereken, hatta birçok ülkede öğrenilmesi teşvik edilen bir branştır (Özgül ve ark., 2015). Çünkü yüzme hayat kurtaran önemli bir yetenek olmakla birlikte çok geniş popülasyonlar(genç, yaşlı, obez, sakat vs.) için sağlık yararı sağlayabilecek bir fiziksel aktivitedir (Chase ve ark., 2008). Amerika ve Avrupa ülkelerinde en popüler fiziksel aktivite yöntemlerinden biri olarak belirtilmektedir (Lahart ve Metsios, 2018). Ancak, popülaritesi ve yarar potansiyeline rağmen yüzme, suyun getirmiş olduğu fiziksel zorluklar (suyun yoğunluğu, basıncı, termal kapasitesi ve iletkenlik gibi) ile güvenlik önlemlerinin alınmasındaki endişeler, egzersiz reçetesi hazırlarken teknik becerideki farklılıklardan kaynaklanan zorluklar nedeniyle bilim literatüründe çok az ilgi görmüştür (Lahart ve Metsios, 2018).

Ülkemizde de yüzme sporu birçok aile tarafından tercih edilmektedir. Okul çağındaki çocukların fiziksel gelişimleri, motor yetenekleri ve genel fiziki parametrelerinin incelenmesi ve sporun bu parametreler üzerindeki etkisinin çok iyi anlaşılması toplumsal hayat standartlarının genişletilmesinde ve toplum sağlığının korunmasında büyük önem taşıyacaktır. Bu nedenle çalışmamızda, yüzme sporu yapan 10-13 yaş grubu çocuklar ile spor yapmayan çocukların antropometrik ve 
fizyolojik özellikleri karşılaştırılmış ve yüzme sporunun etkisinin incelenmesi amaçlanmıştır.

\section{Yöntem}

\section{Araştırma grubu}

Malatya ilinde yaşayan 33 sağlıklı ve gönüllü çocuk iki gruba ayrıldı. Sporcu grubunu (SG); 2 yıl boyunca düzenli yüzme sporu yapan lisanslı 16 yüzücü erkek

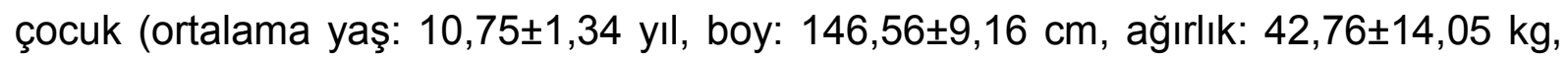
spor yaşı: $26.31 \pm 10.22$ ay) ve kontrol grubunu (KG); herhangi bir spor dalı ile

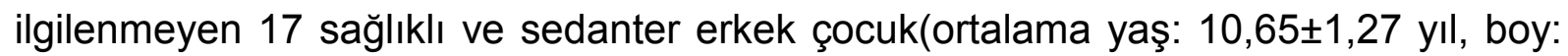

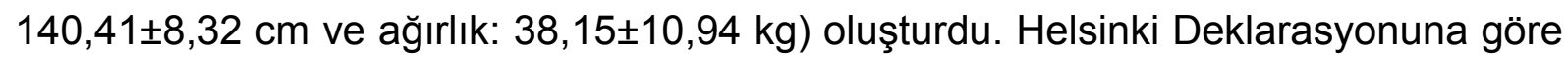
hazırlanmış bilgilendirilmiş gönüllü olur onam formu çalışmaya katılan çocuklara ve velilerine imzalatılmıştır. Gönüllü olarak araştırmaya katılan bütün çocuklar, gerekli sağlık kontrollerinden geçirildikten sonra araştırmaya dahil edilmiştir. Çocukların 1013 yaş arası seçilme nedeni, literatürde hızlı büyüme süreci kızlarda 9.5-15 yaş, erkeklerde 11-17 yaş olarak belirtilmesinden (Baltacı 2008) kaynaklanmaktadır.

\section{Uygulanan Ölçüm ve Testler}

\section{Antropometrik Testler}

Boy uzunluğu: Katılımcıların boy uzunluğu Harpenden marka stadiometre (Holtain, UK) ile ayaklar bitişik ve dik duruşta alınarak cm cinsinden kaydedildi (Güllü ve ark., 2014).

Vücut kompozisyonu: Ağırlık, Beden Kitle Indeksi (BKİ) Bazal Metabolizma Oranı (BMR), Vücut Yağ Kitlesi (VYK) ve Vücut Yağ Yüzdesi (VYY) biyoelektrik impedans analiz (Tanita BC-418 MA Professional, Japan) yöntemi ile otomatik çıktı alınarak belirlendi (Güllü ve ark., 2014).

\section{Uygulanan Testler}

Maksimal oksijen tüketimi ( $\mathrm{MaxVO}_{2}$ ): Koşu bandı üzerinde (Cosmed T-150, İtalya) Bruce Protokolü ile deneklerin testi bıraktıkları seviye takip formuna işaretlendi ve değerlendirme tablosuna bakılarak MaxVO2 seviyeleri $\mathrm{ml} / \mathrm{kg} / \mathrm{dk}$ cinsinden (Mackenzie, 2005) kaydedildi. 
Kan basıncı: Manuel stetoskop ve sphygmomanometre ile Bruce Protokolü öncesi ve sonrası sistolik ve diastolik kan basıncı değerleri $\mathrm{mm} \mathrm{Hg}$ cinsinden (www.tkd.org.tr) kaydedildi.

El kavrama kuvveti (KK): Takei Grip-D (Japonya) marka el dinamometresi ile sağ ve sol el için ayrı ayrı iki kez ölçüm yapılarak en iyi değer kg cinsinden (Mackenzie, 2005) kaydedildi.

Otur eriş testi: Deneklerin esneklik ölçümleri esneklik sehpası kullanılarak otur-uzan (sit-reach) testi ile gerçekleştirilmiştir. Deneklerden iki deneme yapmaları istenmiş ve en iyi dereceleri cm cinsinden (Mackenzie, 2005) kaydedildi.

Sargent dikey sıçrama testi (ST): Denekler, sıçrama sehpasında dikey olarak yukarı doğru sıçramaları istendi ve iki denemeden en iyi dereceleri $\mathrm{m}$ cinsinden kaydedildi. Daha sonra elde edilen sıçrama mesafeleri $P=(\sqrt{ } 4.9 \times$ Ağırlık $\times \sqrt{ } D)$ Lewis formülü kullanılarak her bir deneğin anaerobik güç $(P)$ değerleri $\mathrm{kgm} / \mathrm{sn}$ cinsinden (Fox ve Mathews, 1981; Mackenzie, 2005) belirlendi.

\section{Verilerin Analizi}

Bu araştırma sonucunda elde edilen verilerin aritmetik ortalaması $(X)$, standart sapması (Ss) hesaplanmışve metin içerisinde $(X \pm S s)$ şeklinde verilmiştir. Bruce Protokolü öncesi ve sonrası grup içi sistolik ve diastolik kan basıncı değerleri arasındaki farklarda Paired Samples-t testi, sporcu ve kontrol grupları arasındaki karşılaştırmalarda ise Independent Samples-t test analizi kullanıldı. Elde edilen veriler, SPSS 15.0 istatistik paket programı ile $p<0.05$ anlamlılık düzeyinde değerlendirildi.

\section{Bulgular}

10-13 yaş grubunda yapılan araştırma sonucunda iki gruba ayrılan yüzme sporu yapan erkek sporcu grubu (n:16) ve herhangi bir spor dalı ile ilgilenmeyen sedanter erkek kontrol grubundan (n:17) elde edilen verilerin bulguları tablolar halinde sunulmuştur. 
Tablo 1: Araştırma Grubunun Tanımlayıcı ve Gruplar Arası Değerleri

\begin{tabular}{|c|c|c|c|c|c|c|}
\hline Değişkenler & Grup & $\mathbf{N}$ & $\mathrm{X}$ & Ss & $t$ & Gruplar arası P \\
\hline Yaş (yıl) & $\begin{array}{l}\text { Sporcu } \\
\text { Kontrol }\end{array}$ & $\begin{array}{l}16 \\
17\end{array}$ & $\begin{array}{l}10,75 \\
10,65\end{array}$ & $\begin{array}{l}1,34 \\
1,27\end{array}$ & 0,226 & 0,822 \\
\hline Boy $(\mathrm{cm})$ & $\begin{array}{l}\text { Sporcu } \\
\text { Kontrol }\end{array}$ & $\begin{array}{l}16 \\
17\end{array}$ & 146,56 & $\begin{array}{l}1, L 1 \\
9,16 \\
8,32\end{array}$ & 2,021 & $0,048^{*}$ \\
\hline Ağırlık (kg) & $\begin{array}{l}\text { Sporcu } \\
\text { Kontrol }\end{array}$ & $\begin{array}{l}16 \\
17\end{array}$ & $\begin{array}{l}42,76 \\
38,15\end{array}$ & $\begin{array}{l}14,05 \\
10,94\end{array}$ & 1,054 & 0,300 \\
\hline $\mathrm{BKI}\left(\mathrm{kg} / \mathrm{m}^{2}\right)$ & $\begin{array}{l}\text { Sporcu } \\
\text { Kontrol }\end{array}$ & $\begin{array}{l}16 \\
17\end{array}$ & $\begin{array}{l}19,55 \\
19,12\end{array}$ & $\begin{array}{l}4,83 \\
3,88\end{array}$ & 0,28 & 0,781 \\
\hline BMR(Kcal) & $\begin{array}{l}\text { Sporcu } \\
\text { Kontrol }\end{array}$ & $\begin{array}{l}16 \\
17\end{array}$ & $\begin{array}{l}1426,38 \\
1325,00\end{array}$ & $\begin{array}{l}203,02 \\
188,39\end{array}$ & 1,488 & 0,147 \\
\hline VYY(\%) & $\begin{array}{l}\text { Sporcu } \\
\text { Kontrol }\end{array}$ & $\begin{array}{l}16 \\
17\end{array}$ & $\begin{array}{l}20,77 \\
23,39\end{array}$ & $\begin{array}{l}8,09 \\
5,81\end{array}$ & $-1,076$ & 0,29 \\
\hline Esneklik (cm) & $\begin{array}{l}\text { Sporcu } \\
\text { Kontrol }\end{array}$ & $\begin{array}{l}16 \\
17\end{array}$ & $\begin{array}{l}19,81 \\
17,00\end{array}$ & $\begin{array}{l}5,21 \\
5,98\end{array}$ & 1,437 & 0,161 \\
\hline Sağ El KK (kg) & $\begin{array}{l}\text { Sporcu } \\
\text { Kontrol }\end{array}$ & $\begin{array}{l}16 \\
17\end{array}$ & $\begin{array}{l}23,25 \\
17,24\end{array}$ & $\begin{array}{c}28,32 \\
4,59\end{array}$ & 0,838 & 0,409 \\
\hline Sol El KK (kg) & $\begin{array}{l}\text { Sporcu } \\
\text { Kontrol }\end{array}$ & $\begin{array}{l}16 \\
17\end{array}$ & $\begin{array}{l}17,11 \\
15,67\end{array}$ & $\begin{array}{l}4,51 \\
5,04 \\
\end{array}$ & 0,868 & 0,392 \\
\hline SKB önce $(\mathrm{mmHg})$ & $\begin{array}{l}\text { Sporcu } \\
\text { Kontrol }\end{array}$ & $\begin{array}{l}16 \\
17\end{array}$ & $\begin{array}{l}106,69 \\
113,29\end{array}$ & $\begin{array}{c}11,01 \\
9,78\end{array}$ & $-1,825$ & 0,078 \\
\hline DKB önce $(\mathrm{mmHg})$ & $\begin{array}{l}\text { Sporcu } \\
\text { Kontrol }\end{array}$ & $\begin{array}{l}16 \\
17 \\
\end{array}$ & $\begin{array}{l}67,44 \\
67,71 \\
\end{array}$ & $\begin{array}{c}8,80 \\
10,59 \\
\end{array}$ & $-0,079$ & 0,938 \\
\hline SKB sonra $(\mathrm{mmHg})$ & $\begin{array}{l}\text { Sporcu } \\
\text { Kontrol }\end{array}$ & $\begin{array}{l}16 \\
17\end{array}$ & $\begin{array}{l}119,57 \\
128,29\end{array}$ & $\begin{array}{l}12,55 \\
13,00\end{array}$ & $-1,961$ & $0,039 *$ \\
\hline DKB sonra $(\mathrm{mmHg})$ & $\begin{array}{l}\text { Sporcu } \\
\text { Kontrol }\end{array}$ & $\begin{array}{l}16 \\
17\end{array}$ & $\begin{array}{l}73,62 \\
79,11 \\
\end{array}$ & $\begin{array}{l}7,54 \\
8,49 \\
\end{array}$ & $-1,961$ & $0,039 *$ \\
\hline $\mathrm{MaxVO}_{2}(\mathrm{ml} / \mathrm{kg} / \mathrm{dk})$ & $\begin{array}{l}\text { Sporcu } \\
\text { Kontrol }\end{array}$ & $\begin{array}{l}16 \\
17\end{array}$ & $\begin{array}{l}48,66 \\
39,24\end{array}$ & $\begin{array}{c}12,70 \\
8,72\end{array}$ & 2,497 & $0,018^{*}$ \\
\hline ST (kgm/sn) & $\begin{array}{l}\text { Sporcu } \\
\text { Kontrol }\end{array}$ & $\begin{array}{l}16 \\
17\end{array}$ & $\begin{array}{l}45,27 \\
37,92\end{array}$ & $\begin{array}{l}11,24 \\
11,70\end{array}$ & 1,837 & $0,042^{*}$ \\
\hline
\end{tabular}

Bu çalışmada sporcu ve kontrol grubunun fiziksel ve antropometrik değerleri incelendiğinde; yaş, boy, ağırlık, BKI, VYY ve BMR değerleri benzer olduğundan (Tablo 1), her iki grubun homojen olduğu söylenebilir.

Tablo 2: Araştırma Grubunun Grup İçi Kan Basıncı Değerleri

\begin{tabular}{cllcc}
\hline Grup & Egzersiz & Değişkenler & $\mathbf{t}$ & Grup içi P \\
\hline \multirow{2}{*}{ SG } & Öncesi & Sistolik kan basıncı $(\mathrm{mmHg})$ & $-8,038$ & $0,000^{*}$ \\
& Sonrası & Diastolik kan basıncı $(\mathrm{mmHg})$ & $-2,760$ & $0,015^{\star}$ \\
\multirow{2}{*}{ KG } & Öncesi & Sistolik kan basıncı $(\mathrm{mmHg})$ & $-5,239$ & $0,000^{\star}$ \\
& Sonrası & Diastolik kan basıncı $(\mathrm{mmHg})$ & $-4,093$ & $0,001^{*}$ \\
\hline
\end{tabular}
${ }^{*} p<0.05$ düzeyinde anlamlıdır.

Sporcu ve kontrol grubunun test değerleri karşılaştırıldığında; MaxVO2, dikey sıçrama, Bruce Protokolü sonrası sistolik ve diastolik kan basınç değerlerinde sporcu grubunun lehine anlamlı bir gelişme gözlenmiştir $(p<0.05)$. 


\section{Tartışma ve Sonuç}

10-13 yaş grubunda yüzme sporu yapan erkek çocuklar ile herhangi bir spor dalı ile ilgilenmeyen sedanter erkek çocukların bazı fiziksel, antropometrik ve fizyolojik parametreleri laboratuvar ve alan testleri uygulanarak saptanmış ve elde edilen değerlerin karşılaştırılmaları yapılarak iki grup arasındaki farkın tespit edilmesi ve yüzme sporunun ölçülen parametrelere etki edip etmediği araştırılmıştır.

İnsan gelişiminde en hızlı büyüme çocukluk yaşamın ilk yıllarında ve ergenlik döneminde görülür. Ergenlik dönemi başlarında büyüme hormonu fazla salgılandığı için boy uzaması ve ağırlık artışı çok fazla olmaktadır (Astandrat ve Rodah, 1977; İbiş ve ark., 2004). Diğer yandan Jurimae ve ark., (2007) haftada 6 saat yüzme egzersizi yapan ve yapmayan genç kızları karşılaştırmış ve iki yıl sonra yüzme egzersizi yapan kızların biyolojik büyüme yoğunluğundan sorumlu olan ghrelin hormonunu konsantrasyonunun daha fazla olduğunu saptamışlar. Bizim çalışmamızda yüzme sporu yapan grubun boy uzunluğu yapmayan gruba göre daha uzundur ve bunun da yüzme egzersizinin büyüme hormonunu olumlu yönde etkilediğinden kaynaklandığını söyleyebiliriz.

Araştırmamızda sporcuların vücut ağırlığı spor yapmayan gruba göre daha yüksektir. Egzersizle birlikte sporcuların vücut ağılıklarının daha az olmasının beklenmesine karşın düzenli sporun vücuttaki kas kütlesini arttırmasından kaynaklı (Sarıtaş ve ark., 2017) yüzücü çocuklardaki vücut ağırlığının daha fazla çıkmış olabileceğini düşündürmüştür.

Beden kütle indeksi (BKI) parametresinde, sporcular ile sedanterler arasında istatistiksel olarak anlamlı farkılık bulunamamıştır. Daha önceki çalışmalarda BKİ ile düzenli egzersiz arasında olumlu ilişki olduğunu gösteren çalışmalar mevcut olsa da (Saygın ve ark., 2005; Bilim ve ark., 2016; Sarıtaş ve ark., 2017) düzenli egzersizin etkisinin olmadığını gösteren çalışmalarda mevcuttur (Kurt ve ark., 2010; Poyraz ve ark., 2015; Selçuk ve Karacan, 2017). Ayrıca Bielec ve ark., (2013) iki yıl süre ile takip ettikleri yüzme grubu ile kontrol grubunun vücut kütle indeksleri arasında anlamlı bir fark yaratmadığını bildirmişlerdir. Başka bir araştırmada 14-19 yaş kız çocuklarında 14 hafta ve haftada iki gün yapılan yüzme egzersizinin vücut yağ dokusunda azalma yaratmasına rağmen BKI' de değişiklik olmadığını söylemişlerdir (Sideraviciute ve ark., 2006).

Çalışmamızda esneklik parametresi spor yapanlar lehine daha yüksek çıkmasına karşın, istatistiksel olarak anlamlı bir fark gözlenmemiştir. Saygın ve ark, 
(2015) 10 -12 yaş erkek çocuklara 16 hafta süresince uygulanan hareket eğitimi sonucunda deney grubunun esneklik değerlerinin kontrol grubuna göre daha yüksek çıktığını ve anlamlı fark olduğunu bildirmişlerdir. Başka bir çalışmada 12-13 yaş grubundaki spor yapan ve yapmayan erkeklerin esneklik değerlerine bakıldığında spor yapan grupta daha yüksek olduğunu bulmuşlardır (Bilim ve ark., 2016). Bir başka çalışmada yaz futbol okuluna katılan çocuklar ile kontrol grubu karşılaştııılığında yaz futbol okuluna katılan çocukların esneklik değerlerinde artış olduğu ama istatistiksel bir fark çıkmadığı belirtilmiştir (İbiş ve ark., 2004)

Vücut yağ yüzdesi parametresinde, yüzücüler ile kontrol grubu arasında istatistiksel olarak anlamlı farklılık bulunamamıştır. Vücut yağ yüzdesi sporcularda $20.77 \pm 8.09$ iken sedanterler de 23.39 \pm 5 .81 olarak bulunmuştur. Sarıtaş ve ark, (2017) çocuklarda yaptıkları çalışmada basketbolcular ile sedanter grubu karşılatırmışlar basketbolcularda $20.72 \pm 1.53$ ve sedanterler de $22.61 \pm 1.70$ olarak bulmuşlar ve her iki grup arasında vücut yağ yüzdesi parametresinde anlamlı bir sonuç tespit etmemişlerdir. Bizim sonuçlarımız Sarıtaş ve arkadaşlarının sonuçları ile benzerlik göstermektir. Düzenli yapılan antrenmanlarda vücut ağırlığı ve deri altı yağ dokusu azalırken yağsız kas kütlesinin artması vücuttaki yağ miktarının azaldığını göstermektedir (Bilim ve ark., 2016). Aynı zamanda vücut yağ yüzdesinde anlamlı farkııık bulunmamasının olası sebebi olarak öğrencilerinin beslenme alışkanlıklarından kaynaklandığı düşünülmektedir (Sarıtaş ve ark., 2017).

El kavrama kuvveti özel bir kuvvet alanını oluşturur ve düzenli antrenmanlar ile geliştirilebildiği vurgulanmıştır (Poyraz ve ark. 2015). Çocukların kas gücü, yaş ve cinsiyetle ilişkilidir. Çünkü kas kütlesi ve kas lifi boyutundaki değişikliklere bağlı olarak çocukların olgunlaşmasıyla kas gücünde de bir artış olur (Jaric S, 2002; Markovic ve Jaric, 2004; Rauch ve ark., 2002; Wind ve ark., 2010). Birkaç çalışmada, kavrama kuvveti ile fiziksel uygunluk veya sağlık durumu arasında anlamlı bir ilişkinin olduğu bildirilmiştir (Kerr ve ark., 2006; Thyberg ve ark., 2005; Bohannon, 2008). Faigenbaum ve ark., (2002) haftada 1 ve 2 günlük kuvvet antrenmanı frekanslarını 712 yaş arası 34 erkek çocuk üzerinde çalıştıkları bir araştırmada haftada 2 gün sıklığında olan kuvvet antrenmanının el kavrama kuvvetini arttırdığını belirtmişlerdir.

Daha önce yapılan çalışmalarda 8 haftalık core antrenmanlarının el kavrama kuvvetini geliştirdiği (Dedecan ve ark, 2016) ve en az bir yıl spor geçmişi olan, bir spor kulübünde veya bir spor kursunda düzenli olarak haftada en az iki gün 
antrenman yapan sporcuların el kavrama kuvvetinin spor yapmayan gruba göre daha yüksek olduğu bulunmuştur (Bilim ve ark., 2016).

Bizim çalışmamızda sporcu grubun el kavrama kuvveti spor yapmayan gruba göre daha yüksek çıkmıştır ve yüzme sporunun düzenli spor yapan çocuklarda el kavrama kuvvetini geliştirdiğini söyleyebiliriz.

Dikey sıçrama gücü, patlayıcı gücü ve kas lifi bileşiminin atletik performansın iyi bir ölçüsüdür (Sharma ve ark., 2017). Şahin ve ark., (2016) haftada 3 gün 8 haftalık yapılan koşu ve mini trompolin antrenmanlarının genç erkeklerde dikey sıçrama kuvvetinin geliştiğini bulmuşlardır. Başka bir çalışmada; elit erkek hentbol oyuncularında 12 haftalık yapılan kuvvet ve pliometrik egzersizlerin dikey sıçrama gücünü arttırdığını tespit etmişlerdir (Carvalho ve ark., 2014). Birçok çalışma düzenli yapılan antrenmanların sporcularda dikey sıçrama parametrelerinde artış olduğunu vurgulamıştır (Dedecan ve ark. 2016; Aslan ve ark., 2017; Sarıtaş ve ark. 2017). Bizim çalışmamızda da yüzme antrenmanları yapan sporcuların dikey sıçraması $45,27 \pm 11.24$ ve spor yapmayan grubun $37,92 \pm 11.70$ olarak bulunmuştur ve sonuçlarımız literatür ile paralellik göstererek düzenli yüzme antrenmanın dikey sıçrama kuvvetini arttırdığını söyleyebiliriz.

Maksimal ve supramaksimal fiziksel aktivite sırasında iskelet kaslarının anaerobik enerji transfer sistemlerini kullanarak meydana getirdiği iş kapasitesi anaerobik kapasite olarak (Jonathan ve Euan, 1997) tanımlanmaktadır. 6 haftalık uygun antrenman programları ile anaerobik kapasitenin \%10 civarında artırılabileceği (Medbo ve Burgers, 1997) için çocuklarda anaerobik kapasite, anaerobik aktivite tipi yüklenmelerle sınırlıdır. Bu nedenle düzenli olarak yapılan yüzme antrenmanlarının, sporcu grubunun lehine dikey sıçrama değerlerini geliştirdiği söylenebilir.

Sporcu grubu ile kontrol grubunun Bruce Protokolü testi sonucunda $\mathrm{MaxVO}_{2}$, sistolik ve diastolik kan basıncı değerleri karşılaştırıldığında sporcu grubunun daha yüksek $\mathrm{MaxVO}_{2}$ değerine sahip olduğu gözlenmiştir. Ayrıca sporcu grubunun sistolik ve diastolik kan basıncı değerlerinde spor yapmayan gruba göre olumlu yönde azalma olduğu ve bu parametreleri geliştirdiği görülmüştür $(p<0.05)$. Düzenli antrenmanların kronik etkisi kalp atım hızının azalması ve kalp atım hacminin artmasına neden olmaktadır (Güllü ve Güllü, 2001). Dolayısıyla yüzme, kalp atımı ve solunum hızını yükseltir ve çalışan kas gruplarına fazla kan akımı sağlarken, kan damarlarındaki kan basıncını da artıır. Bu nedenle aerobik egzersizler aynı zamanda kan basınçlarını düzenlemede faydalı egzersiz tipleridir diyebiliriz (Israel, 1983). 
$\mathrm{MaxVO}_{2}$ hem fiziksel performans için hem de genel olarak sağlık için çok önemlidir ve kardiyovasküler solunum uygunluğun bir göstergesi olarak kullanılmaktadır (Doijad ve ark., 2013). Düzenli dayanıkııık ve kuvvet antrenmanları ile $\mathrm{MaxVO}_{2}$ yaklaşık \% 15-20 oranında geliştirilebilir (Sönmez, 2002; De Backer ve ark., 2007; Lovell ve ark., 2009; Arazi ve ark., 2012). Diğer yandan $\mathrm{MaxVO}_{2}$ deki artış direkt olarak antrenmanın frekansına, şiddetine ve süresine bağıı olarak \%5-30 arasında gelişme sağlayabilmektedir (Hickson ve Rosenkdetter, 1984; Astandrat ve Rodahl, 1977). 10-11 yaşlarına kadar kız ve erkek çocuklardaki $\mathrm{MaxVO}_{2}$ gelişimi farklılık gösterdiği (Gaesser ve Rich, 1984) bilinmektedir. Yüzme antrenmanlarının, kardiyovasküler sağlık ve vücut kompozisyonu üzerinde çok sayıda popülasyonda güçlü yararlı etkiler sunduğu (Lahart ve Metsios, 2018) ve bizim çalışma sonucumuzda düzenli olarak yapılan yüzme antrenmanlarının sporcu grubunun $\mathrm{MaxVO}_{2}$ değerinde olumlu gelişmelere neden olabileceği şeklinde açıklanabilir.

Sonuç olarak; yüzme sporunun uzun süre düzenli olarak yapılmasının 10-13 yaş grubu erkek çocuklarda aerobik ve anaerobik kapasiteler ile sistolik ve diastolik kan basıncı parametreleri üzerinde olumlu bir etki sağladığı söylenebilir.

\section{Kaynaklar}

Arazi, H., Farzaneh, E., Gholamian, S. (2012). Effects of Morning Aerobic Training on Lipid Profile, Body Composition, WHR and Vo2max in Sedentary Overweight Females. Acta Kinesiologica, 6 (1), 19-23.

Aslan, C. S., Eyuboğlu, E., Dalkıran, O., Özer, U. (2017). Sedanter kadın ve erkeklerin esneklik değişkenine göre kuvvet ve anaerobik güç özelliklerinin karşılaştırıması. Journal of Human Sciences, 14(4), 4531-45.

Astandrat, P.O., Rodahl, I. (1977), Textbook Of Work Physiology, Mc Graw-Hill Company, N.Y.

Baltacı, G. (2008). Çocuk ve Spor. Sağlık Bakanlığı, 3. Baskı, Klasmat Matbaacılık, Ankara.

Bielec, G., Peczak-Graczyk, A., Waade, B. (2013). Do swimming exercises induce anthropometric changes in adolescents? Issues Compr Pediatr Nurs, 36(12):37-47

Bilim, A.S., Çetinkaya, C., Dayı, A. (2016). 12-17 Yaş Arası Spor Yapan Ve Spor Yapmayan Öğrencilerin Fiziksel Uygunluklarının İncelenmesi." Spor ve Performans Araştırmaları Dergisi, 7(2), 53-60. 
Bohannon, R.W. (2008). Hand-grip dynamometry predicts future outcomes in aging adults. J Geriatr Phys Ther, 31(1),3-10.

Carvalho, A., Mourão, P., Abade, E. (2014). Effects of Strength Training Combined with Specific Plyometric exercises on body composition, vertical jump height and lower limb strength development in elite male handball players: a case study. J Hum Kinet, 8(41), 125-32.

Chase, N.L., Sui, X., Blair, S.N. (2008).Comparison of the health aspects of swimming with other types of physical activity and sedentary lifestyle habits. Int J Aquat Res Educ, (2):151-61

De Backer, I.C., Van Breda, E., Vreugdenhil, A., Nijziel, M.R., Kester, A.D., Schep, G. (2007). High-intensity strength training improves quality of life in cancer survivors. Acta Oncologica, 46(8), 1143-1151

Dedecan, H., Çakmakçi, E., Biçer, M., Akcan, F. (2016). The Effects Of Core Traınıng On Some Physıcal And Physıologıcal Features Of Male Adolescent Students. European Journal of Physical Education and Sport Science, 2(4), 132-144.

Doijad, V.P., Kample, P., Surdi, A.D. (2013).Effect of Yogic exercises on aerobic capacity (VO2 max). International Journal of Recent Trends in Science And Technology, 6 (3),119-121.

Faigenbaum, A.D., Milliken, L.A., Loud, R.L., Burak, B.T., Doherty, C.L., Westcott, W.L. (2002). Comparison of 1 and 2 days per week of strength training in children. Research quarterly for exercise and sport, 73(4), 416-24.

Fox,E.L.\&Mathews, D.K (1981) The Phsiological Basis of Physical Education and Athletics. Philadelphia 61.

Gaesser , G.A., Rich, R.G. (1984),Effectsof High and Low İntesityExercise Training on Aerobic Capacity and Blood Lipids. Medicine andScience in Sports and Execise, 16, 269-274.

Güllü, A., Güllü, E. (2001).Genel Antrenman Bilgisi (Sportif Performansı Geliştirmenin Yolları) 1. Baskı, Umut Matbaacılık, İstanbul.

Güllü, A., Güllü, E., Akçınar, F., Güllü, M., Çiçek, G. (2014). The Effect of 6-Month Fundamental Soccer Training on Body Composition, Soccer Skill and Biomotor Abilities of Aged 10-12 Sedentary Male Children. Journal of Athletic Performance and Nutrition, 1 (1), 10-20 
Haywood, K.M. (1986). Life Span Motor Development. Human Kinetics Pub. Inc., Champaign

Hickson, R.C., Rosenkdetter, M.A. (1981). Reduced Training Freguencies and Maintenance of İncreased Aerobik Power, Med. And Science in Sports and Exercise,13,13-16.

Israel, R.G. (1993). Infulance of Cardiorespiratory Fitness on Measure of Obesity an Fat Distribution in Man, Med. and Science in Sport and Exercise, 25 (5),152.

İbiş, S., Gökdemir, K., İri, R. (2004). 12-14 Yaş Grubu Futbol Yaz Okuluna Katılan Ve Katılmayan Çocukların Bazı Fiziksel Ve Fizyolojik Parametrelerinin Incelenmesi. Kastamonu Eğitim Dergisi,12 (1), 285-292.

Jaric, S. (2002). Muscle strength testing: use of normalisation for body size. Sports Med, 32(10),615-631.

Jonathan, M., Euan, A. (1997). A perspective on exercise, lactate, and the anaerobic threshold. Chest, 111,787-795.

Jurimae, J., Cicchella, A., Jurimae, T., Latt, E., Haljaste, K., Purge, P., Hamra, J., von Duvillard, S.P. (2007). Regular physical activity influences plasma ghrelin concentration in adolescent girls. Medicine \& Science in Sports and Exercise, 39, 1736-1741.

Kerr, A., Syddall, H.E., Cooper, C., Turner, G.F., Briggs, R.S., Sayer, A.A. (2006). Does admission grip strength predict length of stay in hospitalised older patients? Age Ageing, 35(1),82-84.

Kurt, S., Hazar, S., İbiş, S., Albay, B., Kurt, Y. (2010). Orta yaş sedanter kadınlarda sekiz haftalık step-aerobik egzersizinin bazı fiziksel uygunluk parametrelerine etkilerinin değerlendirilmesi. Uluslararası İnsan Bilimleri Dergisi,7(1),666-674.

Lahart, I.M., Metsios, G.S. (2018). Chronic Physiological Effects of Swim Training Interventions in Non-Elite Swimmers: A Systematic Review and Meta-Analysis. Sports Med, 48(2):337-359

Lovell, D.I., Cuneo, R., Gass, G.C. (2009). Strength training improves submaximum cardiovascular performance in older men. J Geriatr Phys Ther, 32(3):117-24.

Mackenzie B. (2005). 101 Performance Evaluation Test. London. Electric Word Plc., 96-117.

Markovic, G., Jaric, S. (2004). Movement performance and body size: the relationship for different groups of tests. Eur J Appl Physiol, 92(1-2),139-149 
Medbo, J.I., Burgers, S. (1986). Effect of Training on the Aerobic Capacity. Medicine and Science in Sports and Exercises, 22(4), 501-507.

Özgül, F., Eliöz, M., Otağ, A., Atan, T. (2015). "Yüzme Sporu Yapan 10-14 Yaş Grubundaki Çocukların Solunum Parametrelerinin Karşılaştırılması" Turkiye Klinikleri J Sports Sci , 7(2):35-40.

Poyraz, A., Baş, O., Ocak, Y., Yıldırım İ., Tortop, Y. (2015). Avrupa Badminton Takım Şampiyonası'na Katılan Sporcuların Bazı Fiziksel Ve Fizyolojik Özelliklerinin Karşılaştırılması, 6 (2), 121-133

Rauch, F., Neu, C.M., Wassmer, G., Beck, B., Rieger-Wettengl, G., Rietschel, E. (2002). Muscle analysis by measurement of maximal isometric grip force: new reference data and clinical applications in pediatrics. Pediatr Res, 51(4), 505510.

Sarıtaş, N., Yıldız, K., ve Hayta, Ü. (2017). İlkokul öğrencilerinin bazı motorik ve fizyolojik özelliklerinin karşılaştırılması. CBÜ Beden Eğitimi ve Spor Bilimleri Dergisi, 12 (2), 117-127

Saygın, Ö., Polat, Y., Karacabey, K. (2005). Çocuklarda Hareket Eğitiminin Fiziksel Uygunluk Özelliklerine Etkisi. F.Ü. Sağlık Bil. Dergisi 2005, 19(3), 205-212.

Selçuk, H., Karacan, S. (2017). 11-13 yaş grubu erkek yüzme sporcularında 12 haftalık terabant antrenmanının yüzme performansına etkileri. Journal of Human Sciences, 14(4), 4958-4968

Sideraviciūte, S., Gailiūniene, A., Visagurskiene, K., Vizbaraite, D. (2006). The effect of long-term swimming program on body composition, aerobic capacity and blood lipids in 14-19-year aged healthy girls and girls with type 1 diabetes mellitus. Medicina (Kaunas), 42(8):661-6

Sharma, H.B., Gandhi, S., Meitei, K.K., Dvivedi, J., Dvivedi, S. (2017).Anthropometric Basis of Vertical Jump Performance: A Study in Young Indian National Players. J Clin Diagn Res, 11(2), CC01-CC05.

Şahin, G., Demir, E., Aydın, H. (2016). Does Mini-Trampoline Training More Effective than Running on Body Weight, Body Fat, VO2 max and Vertical Jump in Young Men. International Journal of Sports Science, 6(1), 1-5.

Thyberg, I., Hass, U.A., Nordenskiold, U., Gerdle, B., Skogh, T. (2005). Activity limitation in rheumatoid arthritis correlates with reduced grip force regardless of sex: the Swedish TIRA project. Arthritis Rheum, 53(6),886-896. 
Türk Kardiyoloji Derneği Ulusal Hipertansiyon Tedavi ve Takip Kılavuzu, erişim: https://www.tkd.org.tr/kilavuz/k03/3 18530.htm?wbnum=1103

Wind, A.E., Takken, T., Helders, P.J., Engelbert, R.H. (2010). Is grip strength a predictor for total muscle strength in healthy children, adolescents, and young adults? Eur J Pediatr, 169(3),281-7.

World Health Organization. Global recommendations on physical activity for health, pg:49.Geneva,2010.

http://apps.who.int/iris/bitstream/10665/44399/1/9789241599979 eng.pdf 